\title{
Calcium Participates in Secretion of Porphyrin from Shell Gland Epithelial Cells of Japanese Quail (Coturnix coturnix japonica)
}

\author{
Osamu Kai \\ Department of Animal Science and Resources, College of Bioresource Sciences, Nihon University, Fujisawa, Japan \\ Email: kai.osamu@nihon-u.ac.jp
}

How to cite this paper: Kai, O. (2019) Calcium Participates in Secretion of Porphyrin from Shell Gland Epithelial Cells of Japanese Quail (Coturnix coturnix japonica). Open Journal of Animal Sciences, 9, 151-161.

https://doi.org/10.4236/ojas.2019.91013

Received: October 5, 2018

Accepted: January 21, 2019

Published: January 24, 2019

Copyright (อ 2019 by author(s) and Scientific Research Publishing Inc. This work is licensed under the Creative Commons Attribution International License (CC BY 4.0).

http://creativecommons.org/licenses/by/4.0/

\begin{abstract}
To investigate factors involved in the secretion of protoporphyrin IX (PpIX), a superficial eggshell pigment, from shell gland epithelial cells of Japanese quail, we cultured cells in Ham's F12 medium with calcium chloride and quail plasma. The addition of hormones (prostaglandin F2 $\alpha$, progesterone, estradiol-17 $\beta$ ) to the medium did not change the PpIX concentration in the culture supernatant, but changing the calcium chloride $\left(\mathrm{CaCl}_{2}\right)$ concentration did: a lower concentration of $\mathrm{CaCl}_{2}$ led to a higher PpIX concentration; $0 \mathrm{mM}$ $\mathrm{CaCl}_{2}$ enhanced the secretion of PpIX from epithelial cells prepared at 5 or 7 $\mathrm{mM} \mathrm{CaCl} 2$. The result suggests that a drop in concentration of $\mathrm{CaCl}_{2}$ mimics the end of shell calcification and stimulates rapid secretion of PpIX in vivo. Bovine serum albumin was almost as effective as quail plasma for PpIX secretion in culture, and would facilitate further study of the mechanism of PpIX secretion.
\end{abstract}

\section{Keywords}

Japanese Quail, Shell Gland Epithelial Cells, In Vitro Culture, Calcium Chloride, Protoporphyrin

\section{Introduction}

Bird eggshell coloring depends on superficial pigments [1] [2] [3] [4]. Japanese quail eggshells are pigmented with protoporphyrin IX (PpIX). The PpIX is accumulated by the shell gland epithelial cells [5] [6] and secreted onto the shell surface 3.5 - $2 \mathrm{~h}$ before oviposition [5] [7] [8]. Factors involved in this process may be oviposition-related hormones such as prostaglandins, arachidonic acid, and arginine vasotocin; hormones injected in vivo induced oviposition and se- 
cretion of the pigment from the shell gland [9], and the level of secretion increased with the dose of prostaglandin F2 $\alpha$ and arachidonic acid [10]. The involvement of prostaglandin was verified by intrauterine injection of indomethacin, which abolished shell pigmentation [11].

An in vitro culture system established to probe PpIX secretion by shell gland epithelial cells [12] can shed further light on the mechanisms. As well as oviposition-related hormones, calcium may be a candidate, because secretion begins when shell calcification ends. The aim of this study was to clarify whether calcium is a factor by using the in vitro culture system.

\section{Materials and Methods}

\subsection{Experimental Birds}

We used Japanese quail $\geq 10$ weeks old and laying on a regular clutch. The quail were individually caged in a windowless environment-controlled room under a cycle of $14 \mathrm{~h} \mathrm{light} / 10 \mathrm{~h}$ dark. Food and water were available ad libitum. The oviposition times of each quail were automatically recorded (Egg Counter, O'Hara \& Co., Ltd. Tokyo, Japan) and estimated oviposition time was calculated from former several days' oviposition time. Quail laying on a regular clutch were selected and used at a certain time before estimated oviposition or after actual oviposition. All procedures were conducted in accordance with the guidelines for animal experiments, College of Bioresource Science, Nihon University.

\subsection{Collection of Egg Shells and Measurement of PpIX}

Eggs were collected at 5,3 , or $0.5 \mathrm{~h}$ before estimated oviposition or $1 \mathrm{~h}$ after oviposition. Shells removed of shell membrane were extracted in $6 \mathrm{~mL}$ hydrogen chloride-methanol solution $(1: 1,20 \% \mathrm{HCl}$ and $100 \%$ methanol) for $24 \mathrm{~h}$ in the dark at room temperature. After centrifugation $\left(1600 \times g, 5 \mathrm{~min}, 4^{\circ} \mathrm{C}\right)$, the supernatant was collected; $100 \mu \mathrm{L}$ was placed in each well of a 96-well culture plate (\#3860-096, Iwaki, Tokyo, Japan) and the fluorescence was determined on a Synergy 2 Multi-Mode Microplate Reader (BioTek Instrument Inc., Winooski, VT, USA) using a 400-nm, 30-nm-bandwidth excitation filter and a 620-nm, 40-nm bandwidth emission filter [12]. The fluorescence intensity was used as the value of PpIX.

\subsection{Isolation of Shell Gland Epithelial Cells and Measurement of PpIX}

The shell gland epithelial cells were collected from the same quails as in 2.2. The cell layer was isolated from the shell gland epithelium as described [12]. In brief, the tissues were placed in Ham's F12 medium (Nissui Pharmaceutical, Tokyo, Japan) with $5 \mathrm{mM} \mathrm{CaCl}_{2}$ (Nacalai Tesque, Tokyo, Japan) and $0.001 \%$ collagenase (Wako, Tokyo, Japan) or in the same volume of Accumax cell dissociation solution (Innovative Cell Technologies, Inc., San Diego, CA, USA). The mixture was cultured in a shaking water bath for $10 \mathrm{~min}$ (collagenase) or $15 \mathrm{~min}$ (Accumax) 
at $37^{\circ} \mathrm{C}$. The cells were centrifuged $\left(30 \times \mathrm{g}, 5 \mathrm{~min}, 4^{\circ} \mathrm{C}\right)$ to wash out the enzyme. The precipitated cells were resuspended in Ham's F12 medium with $5 \mathrm{mM} \mathrm{CaCl}$ and stood for several minutes to allow unseparated tissues to settle out. This process was repeated until the supernatant was clear. Then the supernatant was centrifuged $\left(30 \times \mathrm{g}, 5 \mathrm{~min}, 4^{\circ} \mathrm{C}\right)$ once more. The sediment was used as shell gland epithelial cells in experiments. For some experiments (e.g. Figure 2), unincubated cells were resuspended in Ham's F12 + 20\% $\mathrm{HCl}$ (final, $4 \%$ ), stirred vigorously, and centrifuged $\left(2000 \times \mathrm{g}, 5 \mathrm{~min}, 4^{\circ} \mathrm{C}\right)$, and PpIX in the supernatant was measured promptly as in 2.2 .

\subsection{Culture of Shell Gland Epithelial Cells and Measurement of PpIX}

The isolated epithelial cells collected at $5 \mathrm{~h}$ before estimated oviposition were counted and adjusted to $2 \times 10^{6}$ cells $/ \mathrm{mL}$ in Ham's F12 medium with $5 \mathrm{mM}$ $\mathrm{CaCl}_{2}$. Cell viability was assessed by the trypan blue method. Cells suspension $\left(2 \times 10^{5}\right.$ cells/well $)$ were placed in each of 3 wells per quail in a 96-well culture plate with $10 \mu \mathrm{L}$ pooled plasma (final, $4 \%$ ) taken from normal quail collected at any time (or the sampled quail) or with the same volume of medium as a control (total, $250 \mu \mathrm{L})$ and cultured in an incubator $\left(5 \% \mathrm{CO}_{2}, 37^{\circ} \mathrm{C}\right)$ for $4 \mathrm{~h}$. After incubation, $200 \mu \mathrm{L}$ of culture supernatant was collected and mixed with Ham's F12 + $20 \% \mathrm{HCl}$ (final, 4\%), stirred vigorously, and measured as described in 2.2; the mean value of 3 wells was defined as PpIX secreted from the cells. The remainder in each well was then mixed with $200 \mu \mathrm{L}$ medium (Ham's F12) and centrifuged $\left(30 \times \mathrm{g}, 5 \mathrm{~min}, 4^{\circ} \mathrm{C}\right)$, and the sediment was resuspended in $200 \mu \mathrm{L}$ medium (Ham's $\mathrm{F} 12+20 \% \mathrm{HCl}$ ) as cell samples. PpIX was measured as described in 2.2 and the values were defined as PpIX in the cells.

\subsection{Culture of Shell Gland Epithelial Cells in Hormones or Charcoal-Treated Quail Plasma}

To test the effect of hormones, we individually dissolved Prostaglandin F2 $\alpha$ Tris salt (PGF2 $\alpha$; Sigma, Tokyo, Japan), Progesterone-water soluble (P4; Sigma), and $\beta$-Estradiol-water soluble (E2; Sigma) in $0.22-\mu \mathrm{m}$-filter-sterilized PBS. Five $\mu \mathrm{L}$ of hormones were added at either 200 or $2 \mu \mathrm{M}(\mathrm{PGF} 2 \alpha, \mathrm{P} 4)$ or at either 200 or 2 $\mathrm{nM}$ (E2) to cell suspension (total, $250 \mu \mathrm{L}$ in Ham's F12 medium with $5 \mathrm{mM}$ $\mathrm{CaCl}_{2}$ ). To exclude steroid hormones from plasma, we mixed half of the quail plasma with activated charcoal powder (Wako) at $0.02 \mathrm{~g} / \mathrm{mL}$ overnight with stirring at $4^{\circ} \mathrm{C}$. The sample was centrifuged $\left(1600 \times \mathrm{g}, 20 \mathrm{~min}, 4^{\circ} \mathrm{C}\right)$, then the supernatant was centrifuged again $\left(5000 \times \mathrm{g}, 40 \mathrm{~min}, 4^{\circ} \mathrm{C}\right)$. The supernatant was filtered at $0.45 \mu \mathrm{m}$ and used as charcoal-treated plasma. The other half of the plasma was left untreated. Cells collected at $5 \mathrm{~h}$ before estimated oviposition were cultured as described in 2.4. After incubation, $200 \mu \mathrm{L}$ of culture supernatant was collected and mixed with Ham's F12 + 20\% HCl (final, 4\%), stirred vigorously, and measured as described in 2.2; the values were defined as PpIX secreted from the cells. 


\subsection{Culture of Shell Gland Epithelial Cells in Different Concentrations of $\mathrm{CaCl}_{2}$}

We prepared $1 \mathrm{M} \mathrm{CaCl}_{2}$ solution in Ham's F12 medium, diluted in the medium, and added $15 \mu \mathrm{L}$ of diluted solution to the cell suspension (final, $250 \mu \mathrm{L}$ ) to a final concentration of $2,3,5$, or $7 \mathrm{mM}$. Cells collected at $5 \mathrm{~h}$ before estimated oviposition were prepared and cultured as described in 2.4. After incubation, 200 $\mu \mathrm{L}$ of culture supernatant was collected and measured as described in 2.5; the values were defined as PpIX secreted from the cells.

\subsection{Culture of Shell Gland Epithelial Cells with Bovine Serum Albumin}

We added $25 \mu \mathrm{L}$ of $10 \%$ BSA (Wako) dissolved in sterilized PBS (final, 1\%) or 10 $\mu \mathrm{L}$ of quail plasma to cell suspension collected at $5 \mathrm{~h}$ before estimated oviposition (total, $250 \mu \mathrm{L}$ in Ham's F12 with $7 \mathrm{mM} \mathrm{CaCl}_{2}$ ). After $1 \mathrm{~h}$ incubation, we removed $200 \mu \mathrm{L}$ of culture medium (1st culture) and added $200 \mu \mathrm{L}$ of fresh medium (Ham's F12 with 0,3 , or $7 \mathrm{mM} \mathrm{CaCl}_{2}$ ) and cultured it for a further $2 \mathrm{~h}$ (2nd culture) in an incubator $\left(5 \% \mathrm{CO}_{2}, 37^{\circ} \mathrm{C}\right)$. After incubation, $200 \mu \mathrm{L}$ of culture supernatant was collected and measured as described in 2.5; the values were defined as PpIX secreted from the cells.

\subsection{Data Analysis}

All data obtained from 3 wells per quail were averaged. Data from all experiments were analyzed by Tukey-Kramer's HSD multiple range test or Student's $t$-test. Correlations were tested with Pearson's coefficient. Values were determined to be significant at $P<0.05$.

\section{Results}

\subsection{Appearance of Eggs and Shell Gland Epithelium in Relation to Time of Oviposition}

Figure 1 shows the appearance of eggs and shell gland epithelium at an estimated 5 and $3 \mathrm{~h}$ before oviposition and $1 \mathrm{~h}$ after oviposition. Eggs collected at -3 $h$ varied in appearance.

\subsection{Porphyrin Concentrations in Relation to Time of Oviposition}

The PpIX concentration (indicated by fluorescence intensity) in eggshell increased significantly from $-5 \mathrm{~h}$ to $-3 \mathrm{~h}$ to $+1 \mathrm{~h}$ (Figure 2 ). The concentration in the epithelial cells also increased marginally before oviposition, but decreased greatly at $-0.5 \mathrm{~h}$. At $-3 \mathrm{~h}$, the correlation between eggshells and cells was significantly negative ( $n=7$, Pearson's $r=-0.927, P<0.01 \%)$.

\subsection{Culture of Shell Gland Epithelial Cells}

\subsubsection{Effect of Hormone Addition to Culture Medium on PpIX Secretion from Cells}

To explain the rapid disappearance of PpIX from the epithelial cells just before 

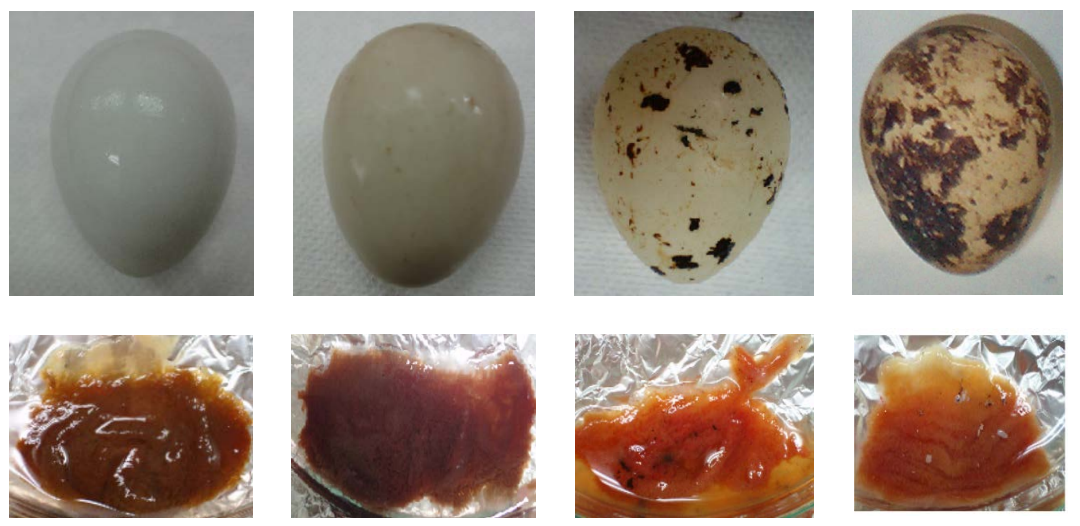

$-5$

$-3$

$+1$

(hours at oviposition )

Figure 1. Photographs of quail eggs (upper panels) and their shell gland tissues (epithelial side, lower panels). Negative times $(-5,-3 \mathrm{~h})$ are based on estimated oviposition calculated from former several days' oviposition time. Eggs and tissues at $-3 \mathrm{~h}$ varied in appearance.

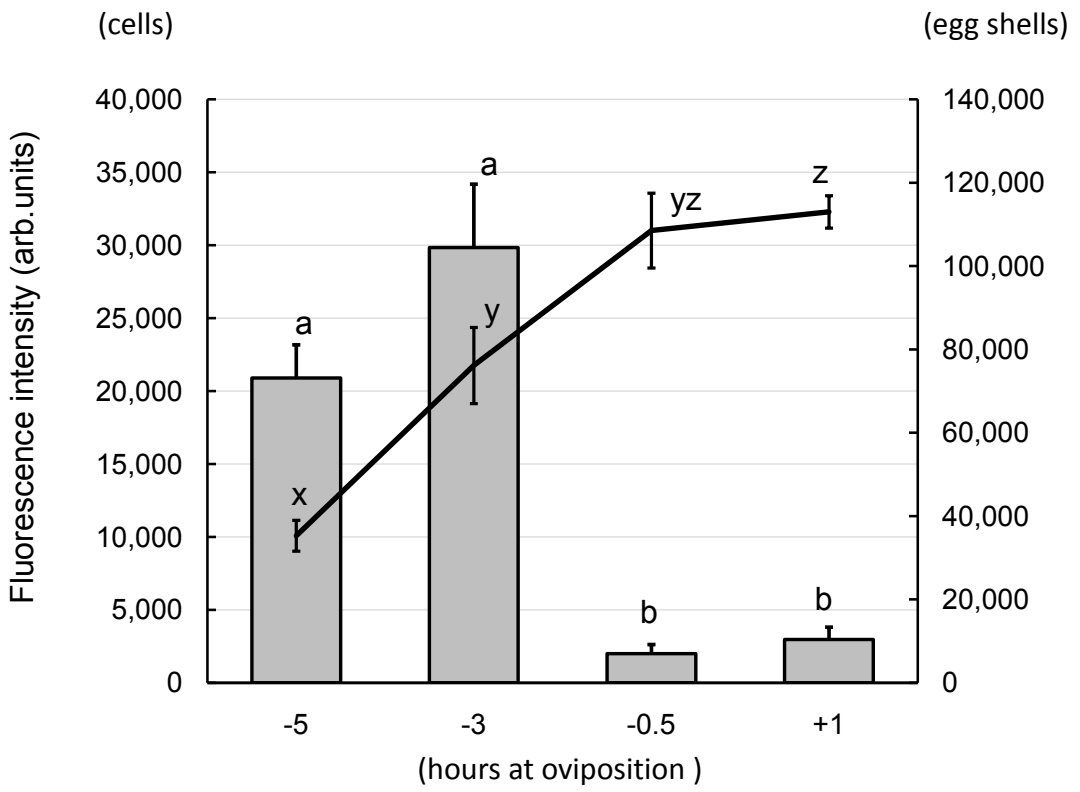

Figure 2. PpIX concentration (shown as fluorescence intensity) of eggshells (line) and epithelial cells (bars) collected at different times in relation to oviposition. Negative times $(-5,-3,-0.5 \mathrm{~h})$ are based on estimated oviposition. Values are means $\pm \operatorname{SEM}(n=3-7)$. Different letters (a, b: cells, $\mathrm{x}, \mathrm{y}, \mathrm{z}$ : eggshells) indicate significant differences $(P<0.05$, Tukey-Kramer's HSD multiple range test).

oviposition (Figure 2), we cultured cells in medium containing charcoal-treated plasma with or without hormones, untreated plasma, or plasma-free medium. None of the hormones had a significant effect on PpIX secretion relative to charcoal-treated plasma (Figure 3). The charcoal-treated plasma had no significant effect relative to untreated plasma. However, the untreated plasma significantly increased secretion relative to plasma-free medium $(P<0.01$, Student's $t$-test). 


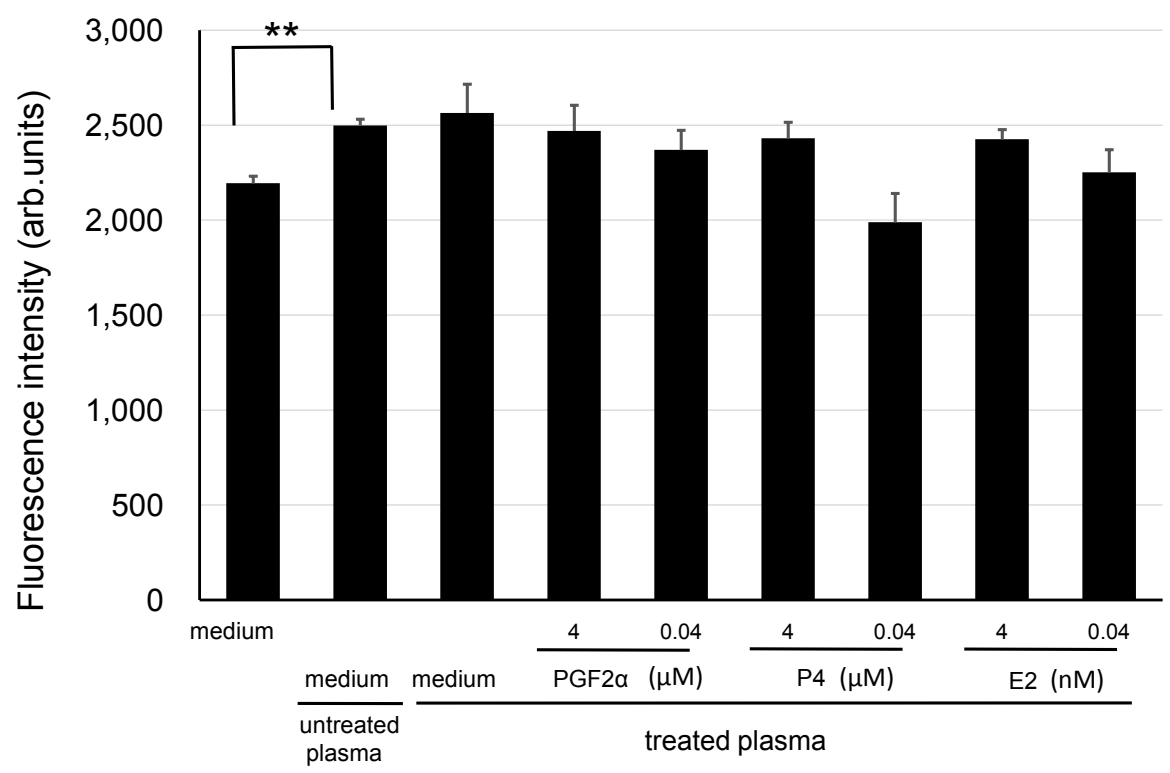

Figure 3. PpIX concentration (shown as fluorescence intensity) in culture medium after incubation of shell gland epithelial cells without or with hormones, charcoal-treated plasma, or untreated plasma. Values are means \pm SEM $(n=3-7)$. There were no significant differences between charcoal-treated plasma and any hormone $(P<0.05$, Tukey-Kramer's HSD multiple range test) or between charcoal-treated plasma and untreated plasma. There was a significant difference between untreated plasma and culture medium ( ${ }^{* *} P<0.01$, Student's $t$-test).

\subsubsection{Effect of $\mathrm{CaCl}_{2}$ Addition to Culture Medium on PpIX Secretion from Cells}

We cultured cells for $4 \mathrm{~h}$ in medium with three concentrations of $\mathrm{CaCl}_{2}$ with or without quail plasma. At $0 \mathrm{~h}$, the PpIX concentrations of the cell culture supernatants were the same in all 6 groups (Figure 4(a)). After 4 h, however, they were much greater with plasma than without, and PpIX was significantly higher at $0 \mathrm{mM} \mathrm{CaCl}_{2}$ than at 2 and $5 \mathrm{mM}$ (Figure 4(b)). The cells, in contrast, had the same PpIX concentration after $4 \mathrm{~h}$ incubation as at $0 \mathrm{~h}$ regardless of the concentration of $\mathrm{CaCl}_{2}$ added to the culture medium (Figure 5).

\subsubsection{Effect of Time of Plasma Collection on PpIX Secretion from Cells}

The plasma used in the culture medium was collected at any time and pooled, or was collected $5 \mathrm{~h}$ before oviposition. So we compared plasma collected $5 \mathrm{~h}$ before oviposition with plasma collected just after oviposition ( 0 h plasma). PpIX concentrations were significantly higher in plasma collected $5 \mathrm{~h}$ before oviposition at all levels of $\mathrm{CaCl}_{2}$ than in plasma-free medium (Figure 6). On the other hand, they were not significantly different between $0 \mathrm{~h}$ plasma and either $5 \mathrm{~h}$ plasma or plasma-free medium (Tukey-Kramer's HSD multiple range test), or among the $\mathrm{CaCl}_{2}$ levels in either plasma treatment (Student's $t$-test).

\subsubsection{Effect of Culture with BSA on PpIX Secretion from Cells}

We tested BSA as a substitute for quail plasma. In the first culture, the PpIX concentration in BSA-medium lay midway between those with and without 


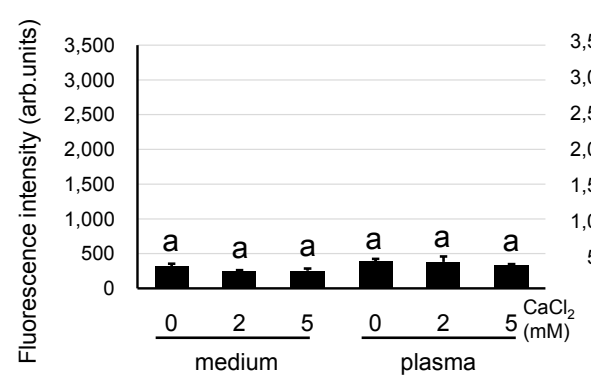

(a)

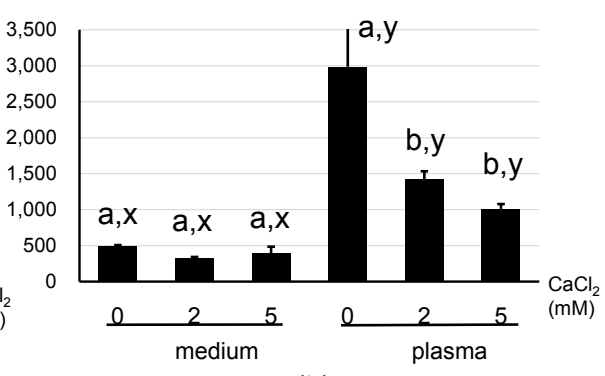

(b)

Figure 4. PpIX concentration (shown as fluorescence intensity) in culture medium after incubation of cells for (a) $0 \mathrm{~h}$ and (b) $4 \mathrm{~h}$ with 0,2 , or $5 \mathrm{mM} \mathrm{CaCl}_{2}$ with ("plasma") or without $4 \%$ plasma ("medium"). Values are means \pm SEM $(n=3)$. At $0 \mathrm{~h}$, there were no significant differences. After $4 \mathrm{~h}$, however, there were significant differences among $\mathrm{CaCl}_{2}$ levels with plasma and between with and without plasma at each $\mathrm{CaCl}_{2}$ level. Different letters indicate significant differences $\left(\mathrm{a}, \mathrm{b}: \mathrm{CaCl}_{2}\right.$ concentrations within plasma treatments, $P<0.05$, Tukey-Kramer's HSD multiple range test; $\mathrm{x}, \mathrm{y}$ : between with and without plasma at each $\mathrm{CaCl}_{2}$ level, $P<0.01$, Student $t$-test).

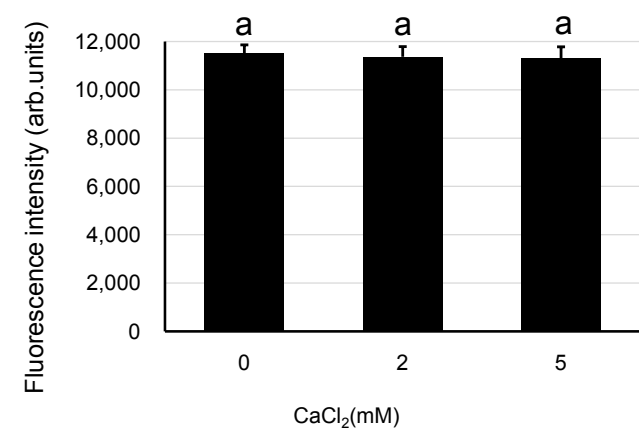

(a)

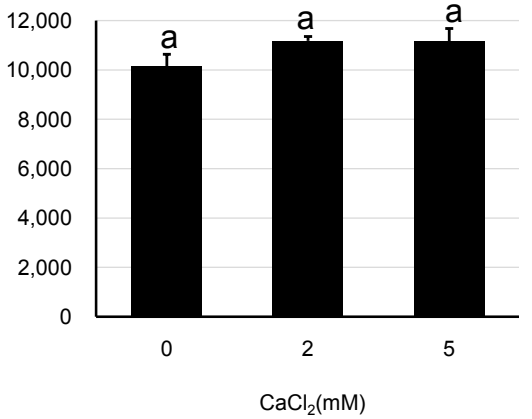

(b)

Figure 5. PpIX concentration (shown as fluorescence intensity) in cells after incubation for (a) $0 \mathrm{~h}$ and (b) $4 \mathrm{~h}$ with 0 , 2, or $5 \mathrm{mM} \mathrm{CaCl}_{2}$ with $4 \%$ plasma. Values are means $\pm \mathrm{SEM}$ $(n=3)$. There were no significant differences (Tukey-Kramer's HSD multiple range test).

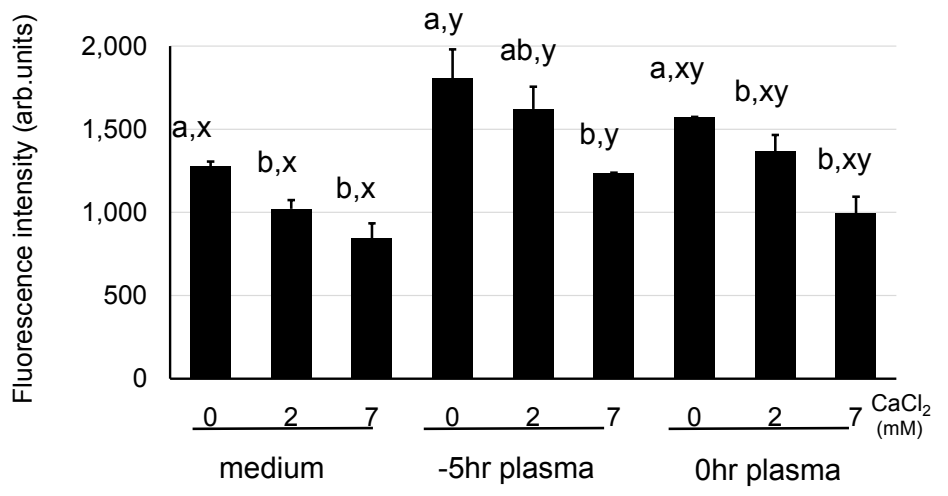

Figure 6. PpIX concentration (shown as fluorescence intensity) in culture medium after incubation of cells for $4 \mathrm{~h}$ in medium without or with $4 \%$ plasma collected $5 \mathrm{~h}$ before oviposition or just after oviposition $(0 \mathrm{~h})$. Values are means $\pm \operatorname{SEM}(n=3)$. Different letters indicate significant differences $\left(\mathrm{a}, \mathrm{b}: \mathrm{CaCl}_{2}\right.$ level within plasma treatment, $\mathrm{x}, \mathrm{y}$ : between plasma treatments within a $\mathrm{CaCl}_{2}$ level, $P<0.05$, Tukey-Kramer's HSD multiple range test). 
plasma (Figure 7(a)). In the second culture, the PpIX concentrations in plasma-medium were significantly higher than those in plasma-free medium at all three $\mathrm{CaCl}_{2}$ levels (Figure 7(b)). Those at 3 and $7 \mathrm{mM} \mathrm{CaCl}_{2}$ were significantly lower in BSA-medium than in plasma-medium, but those at $0 \mathrm{mM} \mathrm{CaCl}_{2}$ groups did not differ significantly between BSA-medium and plasma-medium (Student's $t$-test). Those at all $\mathrm{CaCl}_{2}$ levels in BSA-medium were significantly higher than those in plasma-free medium, respectively (Student's $t$-test).

\section{Discussion}

The shell of the quail egg is unevenly spotted with a superficial layer of pigment formed after shell deposition is complete [5]. The pigment, PpIX, is secreted onto the shell surface $3.5-2 \mathrm{~h}$ before oviposition [5] [7] [8]. The eggshells that we collected about $3 \mathrm{~h}$ before oviposition had a range of pigmentation (Figure 1), and there was a significant negative correlation between PpIX concentrations in eggs and cells collected at that time. These results suggest that secretion of the PpIX from the shell gland epithelial cells onto the shell surface occurs quickly.

In vivo experiments showed that both prostaglandin F2 $\alpha$ and arachidonic acid participate in the events [9] [10], but further evidence requires in vitro experimentation. We developed a method of incubating epithelial cells in vitro and measuring PpIX secretion by a spectrofluorometer [12]. We used that method here to identify factors involved in the secretion of PpIX from epithelial cells. Our results show that the addition of quail plasma to the culture medium significantly increased PpIX in the medium [12], and therefore unidentified factors in the plasma facilitate the secretion of PpIX.

In vivo experiments suggested that the injection of quails with prostaglandin F2 $\alpha$ induced pigmentation [10] and indomethacin inhibited it [11]. However, our results show that neither PGF2 $\alpha$ nor P4 or E2 enhanced the secretion of

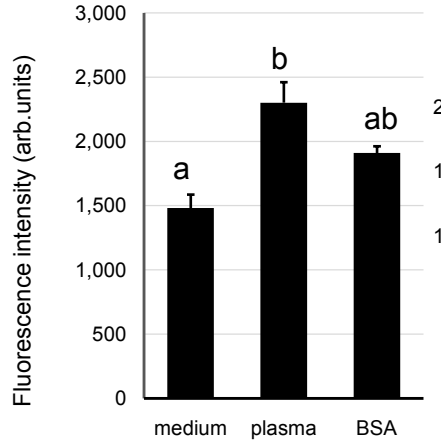

(a)

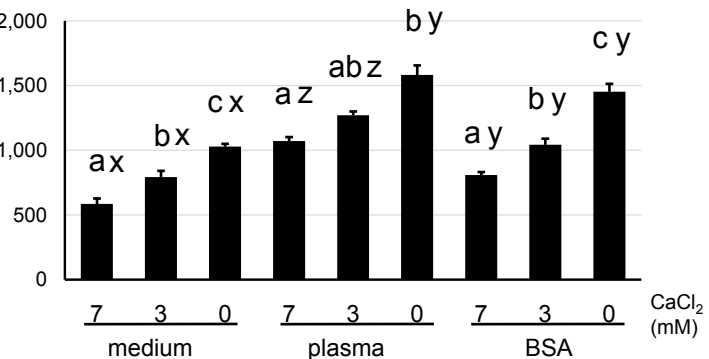

(b)

Figure 7. PpIX concentration (shown as fluorescence intensity) in culture medium after incubation of cells with (a) $4 \%$ plasma or 1\% BSA (in Ham's F12 medium with $7 \mathrm{mM}$ $\mathrm{CaCl}_{2}$ ) for $1 \mathrm{~h}$ and (b) Ham's F12 medium with $4 \%$ plasma or $1 \%$ BSA with 0,3 , or $7 \mathrm{mM}$ $\mathrm{CaCl}_{2}$ for $2 \mathrm{~h}$. Values are means \pm SEM $(\mathrm{n}=4)$. Different letters indicate significant differences (a) a, b: among treatments, $P<0.05$, Tukey-Kramer's HSD multiple range test, (b) a, b, c: among $\mathrm{CaCl}_{2}$ levels within treatment, $\mathrm{x}, \mathrm{y}$, z: among treatments within a $\mathrm{CaCl}_{2}$ level, $P<0.05$, Tukey-Kramer's HSD multiple range test). 
PpIX from epithelial cells. Verification of this result will require a wider range of concentrations used in this study.

Calcium is another candidate, since calcium carbonate is a major component of eggshell, and the shell gland of a laying hen transports $2.0-2.5 \mathrm{~g}$ of Ca within $15 \mathrm{~h}$ for the calcification of a single egg [13]. In white Leghorn hens, the secretion of $\mathrm{Ca}$ from the shell gland increases $\sim 7 \mathrm{~h}$ after ovulation, reaches a maximum as the shell is being formed, and falls to the basal rate after shell formation is complete [14], and the time of pigmentation coincides with the completion of calcification [5]. This role exposes shell gland epithelial cells to high Ca levels during shell formation. To test whether Ca participates in PpIX secretion in vitro, we prepared cells first in a high-Ca environment (Ham's F12 medium +5 $\mathrm{mM} \mathrm{CaCl}{ }_{2}$ ) and then measured secretion in medium with 0 , 2, or $5 \mathrm{mM} \mathrm{CaCl}_{2}$. The secretion of PpIX was significantly higher with $0 \mathrm{mM} \mathrm{CaCl}_{2}$ than with 2 and $5 \mathrm{mM}$ (Figure 4). This result suggests that changing the Ca level from high to low increased the secretion of PpIX by mimicking the environment of the shell gland epithelial cells and the timing of the ending of calcification of the shell in vivo. Therefore, the reduction of the $\mathrm{CaCl}_{2}$ concentration is a factor in the secretion of PpIX from the shell gland epithelial cells.

Since the addition of quail plasma was necessary for enhancing PpIX secretion in vitro (Figure 3, Figure 4, Figure 6), it may be another factor involved in secretion. Domestic poultry, including Japanese quail, have a $\geq 24$-h ovulation-oviposition cycle [13]. Ovarian hormones and other factors in blood change widely within the cycle, so the timing of blood collection is important. However, the secretion of PpIX was slightly but not significantly lower in plasma collected just after oviposition than at $5 \mathrm{~h}$ before oviposition (Figure 6). Further experiments will be necessary to identify other factors in the plasma that affect PpIX secretion.

The use of BSA had comparable effects to the use of quail plasma, especially at $0 \mathrm{mM} \mathrm{CaCl}{ }_{2}$ and after only $2 \mathrm{~h}$ incubation (Figure 7). Ovalbumin at the same concentration also significantly increased PpIX secretion (data not shown). Therefore, albumin in plasma may be an important factor in PpIX secretion. As BSA is widely used in laboratory experiments, its use in place of quail plasma may further the study of PpIX secretion.

To our knowledge, our results represent the first observation of the participation of calcium in the secretion of PpIX from shell gland epithelial cells in vitro. The methodology would be suitable for the in vitro study of secretion mechanisms.

\section{Conclusion}

We used an in vitro cell culture system to identify factors involved in the secretion of PpIX from shell gland epithelial cells of Japanese quail. The PpIX concentration in culture medium containing quail plasma depended on the concentration of $\mathrm{CaCl}_{2}$ but not on the presence or concentration of hormones. The 
rapid drop of $\mathrm{CaCl}_{2}$ concentration in the culture medium might mimic the environment of the cells and the timing of the end of shell calcification in vivo, and thus might be an important factor in triggering PpIX secretion.

\section{Acknowledgements}

I wish to thank Mses. K. Mineo, M. Sensui, Y. Yanagimachi, N. Kitame, E. Shiga and M. Inaba for their help in collecting data.

\section{Conflicts of Interest}

The author declares no conflicts of interest regarding the publication of this paper.

\section{References}

[1] Romanoff, A.L. and Romanoff, A.J. (1949) The Avian Egg. New York, Wiley Co.

[2] Lang, M.R. and Wells, J.W. (1987) A Review of Eggshell Pigmentation. Worlds Poultry Science, 43, 238-246. https://doi.org/10.1079/WPS19870016

[3] Liu, H.-C. and Cheng, W.T.-K. (2010) Egg Shell Pigmentation: A Review. Journal of Chinese Society of Animal Science, 39, 75-89.

[4] Samiullah, S., Roberts, J.R. and Chousalkar, K. (2015) Eggshell Color in Brown-Egg Laying Hens-A Review. Poultry Science, 94, 2566-2575. https://doi.org/10.3382/ps/pev202

[5] Woodard, A.E. and Mather, F.B. (1964) The Timing of Ovulation, Movement of the Ovum through the Oviduct, Pigmentation and Shell Deposition in Japanese Quail (Coturnix coturnix japonica). Poultry Science, 43, 1427-1432. https://doi.org/10.3382/ps.0431427

[6] Tamura, T. and Fujii, S. (1966) Histological Observations on the Quail Oviduct; on the Secretions in the Mucous Epithelium of the Uterus. Journal of the Faculty of Fisheries and Animal Husbandry, Hiroshima University, 6, 357-371.

[7] Poole, H.K. (1965) Spectrophotometric Identification of Eggshell Pigments and Timing of Superficial Pigment Deposition in the Japanese Quail. Proceedings of the Society for Experimental Biology and Medicine, 119, 547-551. https://doi.org/10.3181/00379727-119-30234

[8] Soh, T., Koga, O. and Tanaka, K. (1989) Involvement of Ovulation Mechanism(s) in the Accumulation of Pigment in the Shell Gland of the Japanese Quail (Coturnix coturnix japonica). Poultry Science, 68, 1156-1158. https://doi.org/10.3382/ps.0681156

[9] Soh, T. and Koga, O. (1999) Effects of Phosphate, Prostaglandins, Arachidonic Acid and Arginine Vasotocin on Oviposition and Pigment Secretion from the Shell Gland in Japanese Quail. British Poultry Science, 40, 131-134. https://doi.org/10.1080/00071669987962

[10] Soh, T. and Koga, O. (1999) The Sensitivity of the Shell Gland to Prostaglandin in Quail; on the Secretion of Pigment from the Mucous Epithelium. Animal Science Journal, 70, 170-173.

[11] Soh, T., Fujihara, N. and Koga, O. (2000) The Effect of Indomethacin on the Superficial Pigmentation of Japanese Quail Eggshell. Japanese Poultry Science, 37, 171-174. https://doi.org/10.2141/jpsa.37.171

[12] Kai, O and Mineo, K. (2018) In Vitro Culture of Shell Gland Epithelial Cells in Jap- 
anese Quail (Coturnix coturnix japonica). Open Journal of Animal Sciences, 8, 184-190. https://doi.org/10.4236/ojas.2018.82013

[13] Johnson, A.L. (2000) 22. Reproduction in the Female. In: Sturkie's Avian Physiolo$g y$, 5th Edition, Academic Press, San Diego, 569-596.

[14] Eastin, W.C. and Spaziani, E. (1978) On the Control of Calcium Secretion in the Avian Shell Gland (Uterus). Biology of Reproduction, 19, 493-504.

https://doi.org/10.1095/biolreprod19.3.493 